GLOBAL WATER PATHOGEN PROJECT

PART FIVE. CASE STUDIES

\title{
IS IT SAFE TO USE UNTREATED GREYWATER TO IRRIGATE VEGETABLES IN MY BACKYARD?
}

\section{Fiona Barker}

Monash University

Melbourne, Australia

Joanne O'Toole

Monash University

Melbourne, Australia 


\section{Copyright:}

\section{cc) (1) (2) \\ BY SA}

This publication is available in Open Access under the Attribution-ShareAlike 3.0 IGO (CC-BY-SA 3.0 IGO) license (http://creativecommons.org/licenses/by-sa/3.0/igo). By using the content of this publication, the users accept to be bound by the terms of use of the UNESCO Open Access Repository (http://www.unesco.org/openaccess/terms-use-ccbysa-en).

\section{Disclaimer:}

The designations employed and the presentation of material throughout this publication do not imply the expression of any opinion whatsoever on the part of UNESCO concerning the legal status of any country, territory, city or area or of its authorities, or concerning the delimitation of its frontiers or boundaries. The ideas and opinions expressed in this publication are those of the authors; they are not necessarily those of UNESCO and do not commit the Organization.

\section{Citation:}

Barker, F. and O'Toole, J. (2019). Is it safe to use untreated greywater to irrigate vegetables in my backyard? In: J.B. Rose and B. Jiménez-Cisneros, (eds) Water and Sanitation for the 21st Century: Health and Microbiological Aspects of Excreta and Wastewater Management (Global Water Pathogen Project). (S. Petterson and G. Medema (eds) Part 5: Case Studies), Michigan State University, E. Lansing, MI, UNESCO. https://doi.org/10.14321/waterpathogens.72

Acknowledgements: K.R.L. Young, Project Design editor; Website Design: Agroknow (http://www.agroknow.com)

Last published: March 19, 2019 


\section{Summary}

\section{Highlights}

* We used a conceptual model with published data to estimate pathogen concentrations

* This method can be used to inform guidelines for safe household greywater reuse
* We show that laundry water is safe for household vegetable irrigation in Melbourne

* Method can be used for other scenarios where local pathogen data are not available

* Method accounts for non-outbreak days (no pathogen shedding and zero household risk)

\section{Graphical abstract}

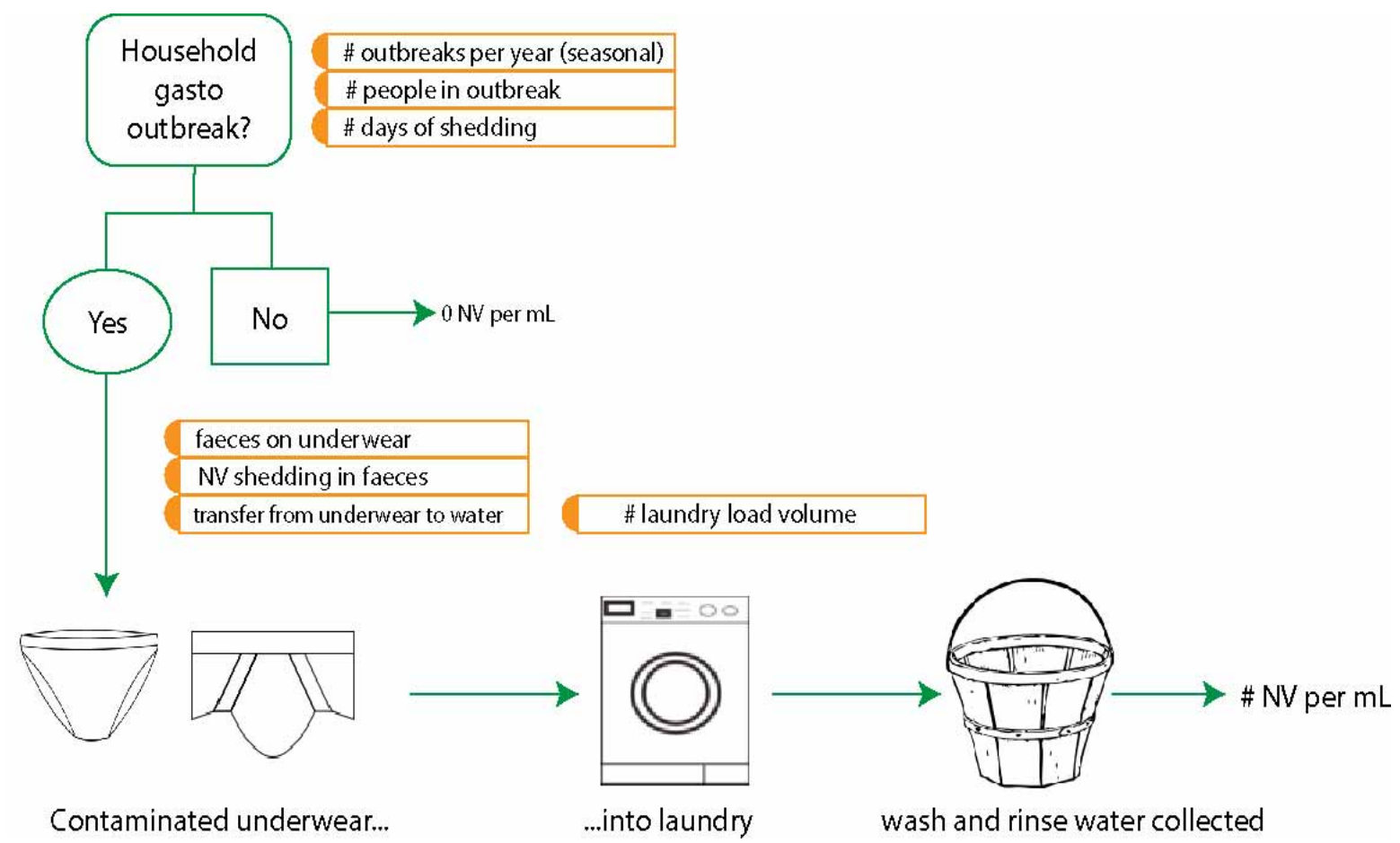

\section{Risk Management Objective}

The objectives of this case study were:

1. to determine if households in Melbourne, Australia can safely reuse on-site greywater for irrigation of vegetables, and

2. to assess if simple control measures are sufficient to reduce risk to acceptable levels.

\section{Location and Setting}

This study took place in Melbourne, Australia where household greywater reuse is common, especially during periods of drought. Greywater can be collected from the shower and laundry and is most often used without any treatment. Household greywater is typically used for outdoor irrigation, including vegetable gardens; however, greywater can be contaminated with enteric pathogens that pose a risk to human health, particularly when used to irrigate food crops such as salad vegetables that are eaten raw. 


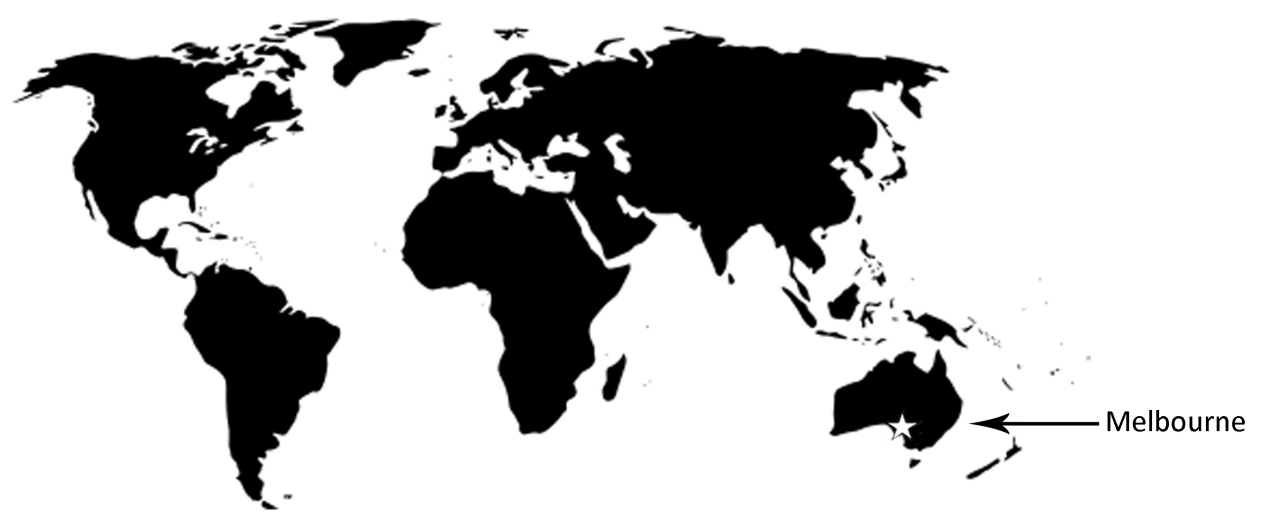

Figure 1. Site location - Melbourne, Australia.

\section{Description of the System}

This study looked at the risk from norovirus, which is the most common cause of community gastroenteritis in Melbourne. In the absence of water quality data, this study demonstrated how to use first principles and available published scientific data to estimate norovirus concentrations in laundry water. The annual disease burden was then estimated for people who eat greywater irrigated lettuce.

\section{Outcome and Recommendations}

This study found that the risk associated with the use of untreated greywater for irrigation of lettuce meets the health risk target when using either the median or the $90^{\text {th }}$ percentile values of disease burden. The use of control measures, including a 2 day withholding period and produce washing prior to consumption, reduced the level of risk but additional measures would be required to meet the health target if using $95^{\text {th }}$ percentile values of disease burden. This case study demonstrates how scientific data can be used to estimate water quality in the absence of local data. It also illustrates the importance of being clear and transparent about the use of statistics (e.g. median, 95th percentile, etc.) as they can significantly impact the assessment of "acceptable" or "unacceptable" levels of risk.

\section{Introduction}

Household use of greywater has become more common, particularly in arid and semi-arid regions of Australia. During severe drought conditions where domestic water restrictions severely limit outdoor tap water use, many Melbourne households turned to the use of greywater to irrigate their gardens with greywater typically collected from showers and washing machines. While greywater is often thought to be relatively harmless, and is typically used untreated, it is well-established that greywater can contain faecal material from shedding during bathing or transferred from towels and clothing in laundry water. Norovirus, which is the most common cause of community gastroenteritis in Melbourne, is transmitted faecal-orally and can survive in water. It has a low infectious dose, a high shedding rate, and high persistence in the environment, and previous studies have demonstrated potential waterborne transmission in drinking water and recreational water.

The use of greywater for household irrigation is likely to remain a common practice during periods of drought in Australia. Therefore, it is important to determine if the use of greywater for irrigation of food crops is safe, in order to provide guidance and recommendations for households. The aim of this case study was to estimate the level of risk associated with household greywater reuse for irrigation of lettuce eaten raw. 


\section{Problem Formulation}

The purpose of this QMRA was to:

determine if irrigation of lettuce with untreated household greywater, collected from the laundry (including both wash and rinse water), is safe; and, if not

determine if simple control measures are sufficient to reduce risk to acceptable levels.

The scope was defined by the following:

Hazard identification: Norovirus was selected as it is the most common cause of community gastroenteritis in Melbourne.

Exposure pathways: Indirect ingestion of untreated greywater through consumption of irrigated lettuce.

Health outcome: DALYs lost per person per year was selected as the health outcome, with a target of $10^{-6}$ DALYs per person.

\section{Exposure Assessment}

Source: Norovirus may be present in laundry greywater if member(s) of the household are infected and/or ill. The concentration of norovirus in greywater was estimated using first principles.

Barriers/controls: The norovirus disease burden from consumption of lettuce irrigated with untreated greywater (comprising both laundry wash and rinse waters) was compared with the implementation of two control measures: cessation of irrigation prior to harvest (withholding period) and washing of lettuce prior to consumption.

Intake: The assumed amount of norovirus ingested during exposure to greywater was determined based upon the estimated volume of greywater indirectly ingested when consuming greywater irrigated lettuce and the concentration of norovirus in the greywater. It was assumed that people ate $23.8 \mathrm{~g}$ of lettuce per day on 251 days per year, and that greywater was retained on lettuce leaves after irrigation.

The concentration of norovirus in greywater was estimated using first principles. As norovirus is transmitted faecalorally, we assumed that underwear was the primary cause of contamination in laundry water. In a 4-person household, we assumed that each laundry load contained 1 pair of underwear from each member of the household. We start by determining the number of norovirus on underwear in a load of laundry during an outbreak (\# per load) as: where $F_{u}$ is the amount of faeces per pair of underwear (grams), $\mathrm{SR}_{\mathrm{NV}}$ is the norovirus shedding rate (number per $\mathrm{g}$ faeces), and $\mathrm{O}$ is the number of people in the household that are ill on a given day (maximum household size is 4 ). The concentration of norovirus in laundry water $\left(\mathrm{C}_{\mathrm{NV} \_ \text {laundry }}\right.$; number. $\mathrm{mL}^{-1}$ ) was then determined as:

$$
C_{N V_{\text {laundry }}}=\left[N V_{\text {underwear }}-\left(N V_{\text {underwear }} 10^{-R_{\text {urius }}}\right)\right] / V_{\text {laundry }}
$$

where $R_{\text {virus }}$ is the viral $\log _{10}$ reduction on fabric due to washing and $\mathrm{V}_{\text {laundry }}$ is the volume of water in a laundry load $(\mathrm{mL})$. On days where no members of the household are ill, the norovirus concentration of greywater is zero (i.e. zero risk of infection).

The number of people in the household that are ill on a given day $(\mathrm{O})$ was estimated using information about the seasonal incidence of household outbreaks (number of outbreaks per month), the number of people infected during a given outbreak (maximum of 4 ), and assuming that infected individuals shed norovirus for 28 days once they are infected. Using this information, we estimated the greywater concentration for 365 days of the year for 10,000 households. There were an estimated 545 outbreaks over a 12 month period for the 10,000 households $(5.3 \%$ of households had at least one outbreak over the 12 months); therefore, the majority (>99\%) of the daily greywater concentration estimates are zero. For example, if a household had an outbreak in January (31 days) with 2 people infected, 28 days of the month would have an estimated greywater concentration where $\mathrm{O}=2$, and 3 days of the month would have a concentration of zero.

The amount, or dose $(\lambda)$, of norovirus ingested indirectly due to eating raw lettuce was estimated as:

$$
\lambda=V I c
$$

where $\mathrm{V}$ is the volume of greywater caught on the surface of a lettuce plant following irrigation (mL per $\mathrm{g}$ ), I is the daily consumption of lettuce (grams per person per day), and $\mathrm{c}$ is the concentration of norovirus in the greywater (number per $\mathrm{mL}$ ). When considering the use of

$$
N V_{\text {underwear }}=F_{u} S R_{N V} O
$$


control measures, the dose of norovirus is estimated as:

$$
\lambda_{w a s h}=V I c 10^{-w} e^{-k t}
$$

where $\mathrm{w}$ is the $\log _{10}$-reduction in virus concentration from washing of lettuce prior to consumption, $k$ is the infield virus kinetic decay constant (per day), and $t$ is the withholding period (days), i.e. time between last greywater irrigation event and harvest.

\section{Health Effects Assessment}

In order to determine if household greywater irrigation is safe, the norovirus dose-response model was used, using the hypergeometric model (Teunis et al., 2008) with a Pfaff transformation, where the probability of infection was calculated as:

$$
P_{\text {inf }}=1-\left[\left({ }_{2} F_{1}\left(\beta, \frac{\lambda(1-a)}{a}, \alpha+\beta ; a\right)\right)\left(\frac{1}{1-a}\right)^{-\left(\frac{\lambda(1-a)}{a}\right)}\right]
$$

where ${ }_{2} F_{1}$ is a hypergeometric function, $\lambda$ is the dose of norovirus (number. $\mathrm{mL}^{-1}$ ), $\alpha$ and $\beta$ are fit parameters and a represents the fit parameter of the (logarithmic series) aggregate size distribution. At doses greater than 33,323 $\mathrm{mL}^{-1}$ the Pfaff transformation fails and so the full BetaPoisson model provides an adequate approximation as follows:

$$
P_{\text {inf }}=1-{ }_{1} F_{1}(\alpha, \alpha+\beta ;-\lambda)
$$

where ${ }_{1} \mathrm{~F}_{1}$ is a confluent hypergeometric function.

Not everyone who becomes infected develops an illness; therefore, a conditional probability of norovirus illness (the proportion of infected individuals developing symptoms of an illness) was calculated using:

$$
P_{i l l \mid \text { inf }}=1-(1+\eta \lambda)^{-r}
$$

where $\eta=0.00255$ and $r=0.086$ (Teunis, Nagelkerke et al. 1999). The daily probability of contracting an illness that would cause some type of disease burden $\left(p_{i l l}\right)$ was calculated as:

$$
P_{i l l}=P_{i n f} \cdot P_{i l l} \mid i n f
$$

The annual probability of contracting an illness (P) that would cause some type of disease burden was calculated as:

$$
P=1-\prod_{k=1}^{d}\left(1-p_{k}\right)
$$

where $p_{k}$ is the kth daily probability of illness per exposure event and $d=215$ days of lettuce consumption per year. A total of 10,000 annual values were calculated.

\section{Risk Characterization}

To incorporate uncertainty and variability, a Monte Carlo simulation with 365 days per year for 10,000 households (total of 3,650,000 iterations) was implemented, using the distributions described above and descriptive statistics (median, 90th and 95th percentile values) were determined. To simplify the model, uncertainty in the days of shedding, lettuce consumption (mass and frequency), and dose-response relationship were not accounted for.

Assuming that the norovirus concentration was zero on days not associated with an outbreak, the median concentration of norovirus in laundry greywater was 0 genomic copies ( $\mathrm{gc}$ ) per mL. Annual risks were expressed in terms of Disability Adjusted Life Years (DALYs), using the recently published Australian norovirus disease burden (B, DALYs per case; Gibney, O'Toole et al. 2014), and using a uniform distribution to account for the range in susceptibilty to norovirus (Sf):

$$
D B=P_{\text {illannual }} B S_{f}
$$

Annual risks were compared against the $10^{-6}$ DALYs per person per year health target.

Using the median value, greywater reuse met the DALY health target; however, using the 95th percentile values, all scenarios exceeded the health target, including those with additional controls of produce washing and withholding periods (Table 1). This highlights the importance of considering which statistic to use in the analysis of risk.

It is important to consider the findings of the QMRA model within the local context. As detailed in the WHO Sanitation Safety Plan (WHO 2016), it is important to consider all exposure and transmission routes. In this case study, while not part of the sanitation system, person-to-person secondary transmission of norovirus may contribute to infection and illness, with reports of $14 \%$ secondary attack rates in households with an infected individual (AlfanoSobsey, Sweat et al. 2012). If it is assumed that irrigated lettuce is consumed only by members of the household, the relative risk from consumption of irrigated lettuce should be considered alongside the risk from exposure within the household. 
Table 1. QMRA results for annual probability of infection per person per year and disability adjusted life years (DALYs) per person per year, reported as median [90th, 95th], for each scenario

\begin{tabular}{|c|c|c|}
\hline Scenario & $\begin{array}{c}\text { Annual probability of } \\
\text { infection }\end{array}$ & DALYs \\
\hline S1 Consumption of greywater-irrigated lettuce. No controls & $0[0,1.00]$ & $0[0,3.8 \mathrm{E}-04]$ \\
\hline S2. S1 plus produce washing as a control & $0[0.1 .00]$ & $0[0,2.5 \mathrm{E}-04]$ \\
\hline S3. S2 plus 1 day withholding period as additional control & $0[0.0 .98]$ & $0[0,1.6 \mathrm{E}-04]$ \\
\hline S4. S2 plust 2 day witholding period as additional control & $0[0,0.92]$ & $0[0,8.6 \mathrm{E}-05]$ \\
\hline
\end{tabular}

\section{Risk Management}

While the reuse of greywater for irrigation of lettuce exceeded the health target when using the 95th percentile values, the health target was easily met using 90th percentile values. Given the context of other household exposure pathways (detailed above), the risk from consumption of greywater irrigated lettuce is low. While the use of controls, such as produce washing are recommended, they had a small impact on the estimated disease burden associated with consumption of greywater irrigated lettuce.

If additional pathogen reductions were required, other controls could be considered. These include:

- the use of better quality greywater sources (i.e. shower or bath water, rather than laundry water),

- dilution of greywater with better quality water (to reduce pathogen loads),

- irrigation of vegetables that are cooked prior to consumption (cooking can reduce the risk from foodborne pathogens), or

- installation of a greywater treatment system.

\section{Evaluation of the QMRA}

This study demonstrated that greywater irrigation of vegetables meets the $10^{-6}$ DALY health target for 90 th percentile estimates. If the aim was to meet the health target at 95th percentile values, additional controls would need to be evaluated as produce washing and a 2 day withholding period were not sufficient.

Regular monitoring of pathogens, or even faecal indicators, may not be practical due to the costs associated with sample collection and analysis. As a result, there may be instances where an assessment of risk is required but no local pathogen data are available. This case study demonstrated how to use first principles and existing published data to estimate pathogen concentrations as part of exploratory assessments of risk. Some of this data can be found in the GWPP chapters [*insert links**].

The use of first principles provides a useful approach to estimating water quality data in the absence of measurements; however, it is very important that model inputs and assumptions are clear and transparent to ensure that the estimates of risk are understood within the appropriate context. For example, while uncertainty and variability were accounted for in this case study by using distributional assumptions, the model results are limited by various assumptions including household size (assumed to be 4) and composition (the outbreak study was conducted in households with 2 children). Further, the broader context of risk should be assessed when conducting a QMRA, which, in this example, includes other pathways of norovirus exposure (i.e. within household person-to-person contact) which may be greater risks of transmission and infection.

\section{Acknowledgements}

This case study was derived from a research project, the results of which are published in the following journal article:

Barker, S. F., J. O'Toole, M. I. Sinclair, M. Malawaraarachchi, K. Leder and A. J. Hamilton (2013). "A probabilistic model of norovirus disease burden associated with greywater irrigation of home-produced lettuce in Melbourne, Australia." Water Research 47: 1421-1432.

Read the full article here: Barker et al., 2013 


\section{References}

Alfano-Sobsey, E., Sweat, D., Hall, A., Breedlove, F., Rodriguez, R., Greene, S. et al. (2012). Norovirus outbreak associated with undercooked oysters and secondary household transmission. Epidemiology and Infection. 140, pp. 276 -282.

Gibney, K., O'Toole, J., Sinclair, M. and Leder, K. (2014). Disease burden of selected gastrointestinal pathogens in Australia, 2010. International Journal of Infectious Diseases. 28, pp. 176-185.

Teunis, P.F.M., Moe, C.L., Liu, P., Miller, S.E., Lindesmith, L., Baric, R.S. et al. (2008). Norwalk virus: how infectious is it?. Journal of Medical Virology. 80, pp. 1468-1476.

Teunis, P.F.M., Nagelkerke, N.J.D. and Haas, C.N. (1999). Dose response models for infectious gastroenteritis. Risk Analysis. 19, pp. 1251-1260.

WHO (2016). Sanitation safety planning - manual for safe use and disposal of wastewater, greywater and excreta. World Health Organization. Geneva. 